\title{
Effect of sodium fluoride and stannous chloride associated with Nd:YAG laser irradiation on the progression of enamel erosion
}

\author{
Samira Helena João-Souza ${ }^{1}$ - Sávio José Cardoso Bezerra ${ }^{2}$ • Alessandra Bühler Borges ${ }^{3}$. \\ Ana Cecília Aranha ${ }^{1}$. Tais Scaramucci ${ }^{2}$
}

Received: 22 April 2015 / Accepted: 16 July 2015 / Published online: 31 July 2015

(C) Springer-Verlag London 2015

\begin{abstract}
This study evaluated the progression of enamel erosion after treatment with gels containing sodium fluoride (NaF; 9047 ppm F) and stannous chloride $\left(\mathrm{SnCl}_{2} ; 3000\right.$ ppm $\mathrm{Sn}$ ), associated or not with Nd:YAG laser irradiation. Sixty enamel specimens were prepared from bovine incisors and protected by a tape, leaving an exposed surface area of $4 \times$ $1 \mathrm{~mm}$. The specimens were immersed in $1 \%$ citric acid $(\mathrm{pH}=$ 2.3) for $10 \mathrm{~min}$ to create an initial erosion lesion. After, they were randomly divided into six groups: $(\mathrm{C})$ control: gel without active ingredient; $(\mathrm{F}): \mathrm{NaF}$ gel; $(\mathrm{F}+\mathrm{Sn}): \mathrm{NaF}+\mathrm{SnCl}_{2}$ gel; (laser): Nd:YAG laser irradiation $(0.5 \mathrm{~W} ; 50 \mathrm{~mJ} ; \sim 41.66 \mathrm{~J} /$ $\left.\mathrm{cm}^{2} ; 10 \mathrm{~Hz} ; 40 \mathrm{~s}\right) ;(\mathrm{F}+$ laser $): \mathrm{NaF}$ gel+Nd:YAG; $(\mathrm{F}+\mathrm{Sn}+$ laser): $\mathrm{NaF}+\mathrm{SnCl}_{2}$ gel $+\mathrm{Nd}: \mathrm{YAG}$. All gels had $\mathrm{pH}=4.5$ and were applied for $1 \mathrm{~min}$. Laser irradiation was performed after gel application. The specimens were then submitted to a 5-day erosion-remineralization cycling model using $1 \%$ citric acid $(\mathrm{pH}=2.3)$, six times per day. Enamel surface loss (SL) was analyzed by optical profilometry in the end of the cycling (in $\mu \mathrm{m})$. Data were analyzed by one-way ANOVA and HolmSidak tests (alpha $=0.05)$. The control and the laser groups presented the highest enamel loss (means $\pm \mathrm{SD}=53.52 \pm 3.65$ and $53.30 \pm 2.73$, respectively), followed by $\mathrm{F}+\mathrm{Sn}(44.76 \pm$
\end{abstract}

Tais Scaramucci

tais.sca@usp.br

1 Special Laboratory of Lasers (LELO), Department of Restorative Dentistry, School of Dentistry, University of São Paulo, Av. Prof. Lineu Prestes 2227, São Paulo, SP 05508-000, Brazil

2 Department of Restorative Dentistry, School of Dentistry, University of São Paulo, Av. Prof. Lineu Prestes 2227, São Paulo, SP 05508-000, Brazil

3 Department of Restorative Dentistry, Univ. Estadual Paulista, Av. Eng. Francisco José Longo 777, Jardim São Dimas, São José dos Campos, SP 12245-000, Brazil
2.83). The groups $\mathrm{F}(36.76 \pm 2.28), \mathrm{F}+$ laser $(36.25 \pm 3.59)$, and $\mathrm{F}+\mathrm{Sn}+$ laser $(39.83 \pm 4.62)$ showed the lowest enamel loss, with no significant difference among them $(p>0.05)$. In conclusion, $\mathrm{NaF}$ by itself or associated with $\mathrm{SnCl}_{2}$ and $\mathrm{Nd}: Y A G$ laser was able to reduce enamel erosion progression. Nd:YAG laser alone did not show a protective effect.

Keywords Tooth erosion · Sodium fluoride $\cdot$ Stannous chloride $\cdot \mathrm{Nd}$ :YAG laser $\cdot$ Optical profilometry

\section{Introduction}

The frequent contact of non-bacterial acids on the tooth surfaces can result in its chemical dissolution, a process known as dental erosion [1]. When this process is associated with physical insults, such as toothbrushing, the tooth can undergo a chemical-mechanical wear process, known as erosive tooth wear [2]. The prevalence of erosive tooth wear is thought to be increasing; this has been attributed to the overall increase in the consumption of acidic foods and drinks and to the changes in perception of this condition by dental professionals over the last few years [3]. When the enamel surface is frequently exposed to erosive acids, a demineralization extending a few micrometers below the surface occurs [4]. This demineralized and softened layer is more vulnerable to physical impacts [2]. As a result of the continuous acid exposure or the physical impacts, the next step in the process is a bulk loss of the tooth surface, leaving a softened layer [4].

To reduce the rate of erosive wear, the use of topical fluoride compounds has been suggested, with effective protection being observed for formulations containing fluoride and stannous [5]. Highly concentrated formulations of monovalent fluoride compounds, such as sodium fluoride, can protect the enamel against dental erosion, which is most likely as 
a result of the formation of $\mathrm{CaF}_{2}$-like precipitates [6]. Polyvalent metal fluoride compounds, such as $\mathrm{SnF}_{2}$, have the ability to react with the enamel surface to form more acid-resistant precipitates [7], which further contributes to its anti-erosive effect [8]. Moreover, under erosive conditions, it was demonstrated that the stannous ion can also incorporate into the enamel structure, and this may be one of the reasons for improved protection [8]. Fluoride can also be applied in a wide range of vehicles. The advantage of in-office treatments, such as varnishes and gels, is that the therapy does not depend on patient's compliance, in addition to the use of higher fluoride concentrations. It should be mentioned, however, that there is a discussion on whether the low-frequency application of such products would be enough to be clinically effective [5]. Thus, the increase of fluoride retention on tooth surface and, consequently, the improvement on its erosion protection is desirable for in-office treatments.

High-power laser irradiation is also an in-office therapy that has been proposed to prevent dental erosion [9-12]. Despite the exact mechanism in which lasers protect the tooth against demineralization has still not been completely elucidated, it is hypothesized that high-power lasers can alter the tooth's mineral content, reducing its solubility and permeability [13]. Regarding the Nd:YAG laser, a previous study showed that it has the ability to promote melting and resolidification of the enamel surface [14], reducing the interprismatic spaces, and thereby the diffusion pathways of acids during an acid challenge [15]. When combined with fluoride, laser irradiation can potentially improve fluoride deposition and uptake by dental substrates [16-20], and this can be relevant for erosion prevention, as shown by previous investigations $[11,12]$. Nevertheless, there are only few studies that have tested the association of laser irradiation with metal fluoride compounds. Wiegand et al. postulated that $\mathrm{CO}_{2}$ laser irradiation would melt and condense the glazedlike layer formed on the tooth surface after the application of titanium tetrafluoride and that this would be translated into improved protection [21]. However, the authors failed to observe such effect. In this study, it is hypothesized that $\mathrm{Nd}$ :YAG laser irradiation would improve the protection provided by the fluoride and stannous chloride against enamel erosion progression, possibly by increasing the retention of both ions on the eroded enamel surface.

Thus, the aim of this in vitro study was to evaluate the influence of Nd:YAG laser irradiation on the protective effect of gels containing sodium fluoride and/or stannous chloride against enamel erosion progression.

\section{Material and methods}

\section{Experimental design}

This study followed a completely randomized design, with a single experimental factor - enamel treatment-at 6 levels: 1 - control (gel without active ingredient, $\mathrm{pH}=4.5$ ); 2 - sodium fluoride $(\mathrm{NaF})$ gel (containing approximately $9047 \mathrm{ppm} \mathrm{F}$, $\mathrm{pH}=4.5) ; 3-\mathrm{NaF}+$ stannous chloride $\left(\mathrm{SnCl}_{2}\right)$ gel (approximately 9047 ppm F and 3000 ppm Sn; pH=4.5); 4 -laser (Nd:YAG laser irradiation; $0.5 \mathrm{~W} ; 50 \mathrm{~mJ} ; \sim 41.66 \mathrm{~J} / \mathrm{cm}^{2}$; $10 \mathrm{~Hz} ; 40 \mathrm{~s}$; in contact); 5-F+laser ( $\mathrm{NaF}$ gel+Nd:YAG laser irradiation); and 6- $\mathrm{F}+\mathrm{Sn}+$ laser $\left(\mathrm{NaF}+\mathrm{SnCl}_{2}\right.$ gel $+\mathrm{Nd}: \mathrm{YAG}$ laser irradiation). Eroded enamel bovine specimens were the experimental units. Enamel surface loss (in $\mu \mathrm{m}$ ), evaluated by optical profilometry at end of the experiment, was the response variable.

\section{Experimental gels}

Table 1 shows the composition of the experimental gels tested. For the $\mathrm{NaF}$ gel, the concentration that is usually present in in-office products was chosen [22]. For the Sncontaining gels, the Sn concentration was chosen based on a previous investigation [23]. As the negative control, a placebo gel, with no active ingredients, was used. The $\mathrm{pH}$ of all the gels was adjusted to 4.5 , with either $1 \mathrm{M}$ $\mathrm{NaOH}$ or $0.1 \mathrm{M} \mathrm{HCl}$ solutions, to avoid having the $\mathrm{pH}$ as a confounding factor.

Table 1 Experimental gels, their composition, and concentration of the reagents used

\begin{tabular}{lll}
\hline Experimental gels & Reagents & Concentration (in g/l) \\
\hline Placebo (control) & Carboxymethyl cellulose $(\mathrm{CMC})^{\mathrm{a}}$ & 100 \\
$\mathrm{~F}$ & $\mathrm{CMC}+$ sodium fluoride $(\mathrm{NaF})^{\mathrm{b}}$ & $100+20$ \\
$\mathrm{~F}+\mathrm{Sn}$ & $\mathrm{CMC}+\mathrm{NaF}+$ gluconic acid $\left(\mathrm{C}_{6} \mathrm{H}_{11} \mathrm{NaO}_{7}\right)^{\mathrm{c}}+$ stannous chloride $\left(\mathrm{SnCl}_{2}\right)^{\mathrm{d}}$ & $100+20+2.3+4.8$ \\
\hline
\end{tabular}

${ }^{\text {a }}$ Carboxymethyl cellulose sodium salt (Sigma-Aldrich Co., St Louis, MO, USA)

${ }^{\mathrm{b}}$ Sodium fluoride (Sigma-Aldrich Co)

${ }^{\mathrm{c}}$ D-gluconic acid sodium salt (Sigma-Aldrich Co.) was added for stability purposes

${ }^{\mathrm{d}}$ Stannous chloride (Sigma-Aldrich Co.) 


\section{Specimen preparation}

Bovine incisors were stored in $0.1 \%$ thymol solution, under refrigeration at $4{ }^{\circ} \mathrm{C}$, until the beginning of the experiment. They were cleaned with Gracey curettes and submitted to prophylaxis with a Robinson's brush coupled in a low-speed hand piece, pumice stone and water. After cleaning, the specimens were stored in distilled water at $4{ }^{\circ} \mathrm{C}$. Enamel slabs of $4 \times 4 \times 2 \mathrm{~mm}$ were cut from the buccal surfaces of the teeth using a microtome (Isomet, Buehler, Lake Bluff, IL, USA). The slabs were embedded in acrylic resin (Varidur, Buehler). The resulting blocks were ground flat and polished, using the following sequence of abrasive papers: $600,1200,2400$, and 4000 grit (Buehler), under constant water cooling. At the end of the polishing procedure, the specimens underwent an ultrasonic bath with deionized water, for $3 \mathrm{~min}$. Specimens without fractures or any other visual imperfections were selected.

\section{Profilometric analysis}

After preparation of the specimens, they were submitted to profilometric analysis to select specimens with a curvature $<0.3 \mu \mathrm{m}$. This analysis was performed with an optical profilometer (Proscan 2100, Scantron, Venture Way, Tauton, UK). The instrument sensor scanned an area that was $2 \mathrm{~mm}$ long ( $X$-axis) and $1 \mathrm{~mm}$ wide ( $Y$-axis), located at the center of the specimen. The equipment was set to go through 200 steps in the $X$-axis, with each step measuring $0.01 \mathrm{~mm}$. In the $Y$-axis, there were 20 steps measuring $0.05 \mathrm{~mm}$ each. The curvature was calculated based on the subtraction of the mean height of the future test area from the mean height of the two reference surfaces using a dedicated software (Proscan Application software v. 2.0.17). Unplasticized polyvinyl chloride (UPVC) tapes were then placed on the selected specimens' polished surfaces, leaving a central window of $4 \times 1 \mathrm{~mm}$ exposed for subsequent testing.

\section{Initial lesion creation}

To create the initial lesion, specimens were fixed to the lid of 12-well culture plates with sticky wax. They were then immersed in $5 \mathrm{ml}$ of $1 \%$ citric acid (Sigma-Aldrich; $\mathrm{pH} \sim 2.3$ ) solution, for $10 \mathrm{~min}$, at room temperature. After that, the specimens were rinsed with deionized water, the tapes were removed, and they were submitted to a second profilometric analysis (using the same parameters described before) in order to check the consistency of the lesions created. The mean enamel loss for the specimens was $3.96 \mu \mathrm{m}(\mathrm{SD}=0.55)$. The specimens were then randomly divided into the six experimental groups $(n=10)$. Subsequently, the tapes were repositioned on the polished surface of the specimens for the experimental procedures.

\section{Treatments}

For the experimental gels, $3 \mathrm{~g}$ were applied on the test surface of the specimens (exposed area), with the aid of a disposable applicator, for $1 \mathrm{~min}$. The excess of the gel was removed with a cotton roll. For the groups treated with Nd:YAG laser associated with fluoride, the gel was applied before irradiation and the excess removed.

Irradiation with the Nd:YAG laser (Power Laser ${ }^{\mathrm{TM}}$ ST6, Lares Research ${ }^{\circledR}$, Chico, CA, USA) was performed on the test area, perpendicular to the specimen surface, with sweeping motion, in contact and focused, using a $400-\mu \mathrm{m}$ quartz fiber. The parameters used were the following: power of $0.5 \mathrm{~W}$; $50 \mathrm{~mJ}$ of energy per pulse; $\sim 41.66 \mathrm{~J} / \mathrm{cm}^{2}$ of energy density; and $10 \mathrm{~Hz}$ of repetition rate. The irradiation was intended to cover the entire region of the formed lesion. The procedure was conducted in four 10-s irradiations (two in up and down movements and the other two, in a left to right direction). An interval of $10 \mathrm{~s}$ between the irradiations was necessary for thermal relaxation of the enamel tissue [24]. Before all irradiation procedures, power output measurements were taken with a power meter (Coherent, Newport, USA), without power loss during any of the irradiations performed.

After treatment, the specimens underwent a third profilometric analysis, which had the objective to verify if the laser had caused any ablation on the enamel tissue. The mean enamel loss obtained in this analysis, for all the groups, was $4.03 \mu \mathrm{m}(\mathrm{SD}=0.47)$, showing that the laser irradiation did not cause enamel ablation.

\section{Erosive cycling}

The tapes were placed on the polished surfaces and then were re-mounted on the lid of the cell culture plates for the erosive cycling procedure, which consisted of a 5-min immersion in $1 \%$ citric acid $(\mathrm{pH} \sim 2.3)$ followed by a 60 -min immersion in artificial saliva $(\mathrm{pH}=7)$. This procedure was repeated six times a day, for 5 days. The citric acid solution was changed after each demineralization cycle (six times per day). Artificial saliva [25] was changed at the beginning of each cycle (once a day). At the end of the cycling, a final profilometric analysis was made, according to the parameters described previously.

\section{Statistical analysis}

Enamel surface loss data, obtained at the end of the experiment, were analyzed for normal distribution and homoscedasticity with Shapiro-Wilk and Brown-Forsythe test, respectively. As both assumptions were satisfied, the comparison among groups was performed with one-way ANOVA and HolmSidak tests. The significance level was set at $5 \%$. SigmaPlot 13 software (Systat Software Inc., Chicago, IL, USA) was used for the calculations. 


\section{Results}

The means (SD) of surface loss data are presented in Fig. 1. The control (C) and the laser groups showed the highest values of enamel loss (means $\pm \mathrm{SD}=53.52 \pm 3.65$ and $53.30 \pm$ 2.73 , respectively), with no significant difference between them. Groups $\mathrm{F}+$ laser $(\mathrm{mean} \pm \mathrm{SD}=36.25 \pm 3.59), \mathrm{F}$ (mean \pm $\mathrm{SD}=36.76 \pm 2.28)$, and $\mathrm{F}+\mathrm{Sn}+$ laser $(\mathrm{mean} \pm \mathrm{SD}=39.83 \pm$ 4.62) presented the lowest enamel loss, followed by $\mathrm{F}+\mathrm{Sn}$ (mean $\pm \mathrm{SD}=44.76 \pm 2.83$ ).

\section{Discussion}

The hypothesis of this study stating that Nd:YAG laser irradiation would improve the protection provided by fluoride and stannous chloride gels against enamel erosion progression had to be partially accepted, as laser irradiation increased the protective effect of the $\mathrm{F}+\mathrm{Sn}$ gel; however, the group $\mathrm{F}+\mathrm{Sn}+$ laser did not differ significantly from groups $\mathrm{F}$ and $\mathrm{F}+$ laser, which were also similar between them.

When combined with fluoride, stannous can interact with the enamel surface and form precipitates, such as $\mathrm{CaF}_{2}$, $\mathrm{Sn}_{2} \mathrm{OHPO}_{4}, \mathrm{Sn}_{3} \mathrm{~F}_{3} \mathrm{PO}_{4}$, and $\mathrm{Ca}\left(\mathrm{SnF}_{3}\right)_{2}$ [7], which can act as mechanical obstacles against an acid attack. After demineralization and remineralization cycles, stannous can also be incorporated into the enamel structure, and this may further contribute to its protective effect [8]. In this sense, it can be supposed that, in the present investigation, the Nd:YAG laser melted the surface containing these aforementioned precipitates, and upon re-solidification, the F and Sn compounds became incorporated into the enamel's structure, thus improving its acid resistance. Nevertheless, in the absence of $\mathrm{Sn}$, $\mathrm{Nd}$ :YAG laser irradiation could not enhance the protective effect of fluoride, as group $\mathrm{F}$ did not differ from $\mathrm{F}+$ laser. This result is in agreement with the findings made by Rios et al.
[11], in which after 5 days of erosion-remineralization cycles, it was observed that Nd:YAG laser irradiation using a protocol of $0.75 \mathrm{~W}$ power did not improve the protection of fluoridated gel against enamel loss. Despite this study used a distinct $\mathrm{Nd}$ :YAG laser equipment with a different fiber and different power setting, the energy density was close to that used in the present study ( $\sim 52.5$ and $\sim 41.7$, respectively). Another study also observed that the Nd:YAG laser did not improve the effect of $\mathrm{NaF}$ (either as solution or varnish) [26]. In this study, laser irradiation only improved the protective effect of a $\mathrm{TiF}_{4}$ solution when the specimens were irradiated prior to $\mathrm{TiF}_{4}$ application. The authors hypothesized that laser irradiation could have removed the carbonate apatite from the enamel surface, leaving spaces in which more fluoride and titanium ions would be incorporated, further contributing to the formation of a titanium-rich acid-resistant layer. This same theory could be applied in the present study, as the laser irradiation also improved the protective effect of Sn gel, although the laser was applied after the gel. It should be mentioned, however, that the energy density used previously in that study was higher than this investigation. Since the authors did not perform profilometric measurements after the irradiation, the effects of this higher energy density on the enamel surface are not known.

Majori et al. [27] and Bedini et al. [28] evaluated the effect of Nd:YAG laser irradiation on enamel surface, and both studies showed that power settings lower than $0.6 \mathrm{~W}$ did not cause tissue damage, as it preserved its integrity in addition to forming a protective layer that can potentially reduce demineralization. In order to increase enamel resistance to dental erosion without causing ablation, this study used a power of $0.5 \mathrm{~W}$, resulting in an energy density of $\sim 41.66 \mathrm{~J} / \mathrm{cm}^{2}$, which is within the safe range previously tested $[27,28]$. To corroborate to this fact, the profilometric analysis performed after treatments showed that there were no surface loss after laser irradiation. Nonetheless, Nd:YAG laser irradiation alone, with
Fig. 1 Means (SD) of enamel surface loss for all the experimental groups. Different letters imply significant difference among groups $(p<0.05)$
70

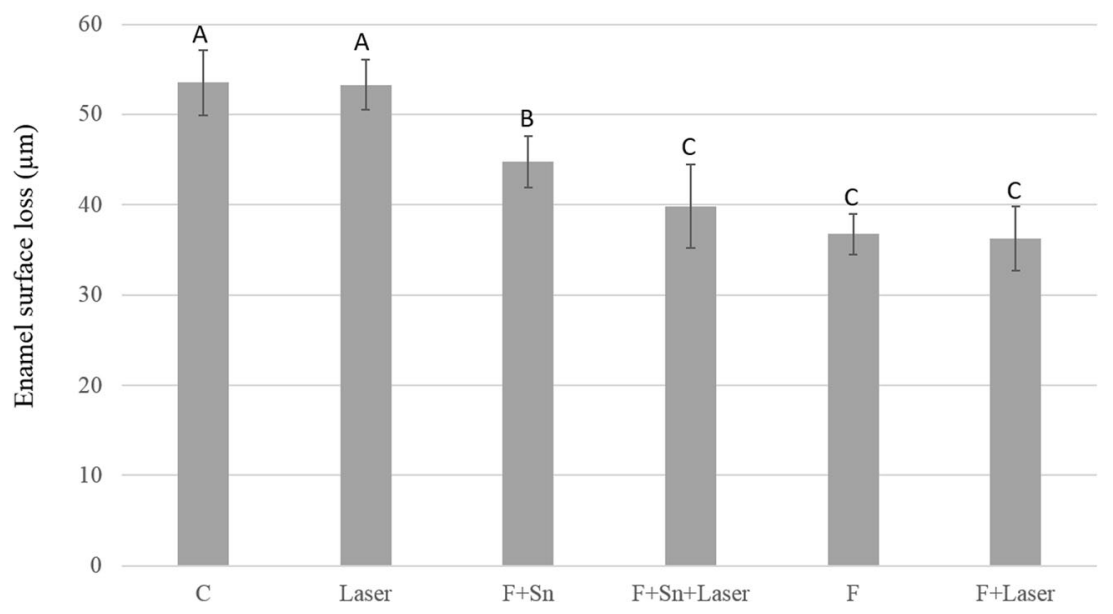


this parameter, did not exhibit any capacity to reduce enamel erosion.

Many studies have shown beneficial effects of the Nd:YAG laser irradiation against enamel demineralization [29-31], but these findings are mostly related to dental caries. Considering the more aggressive nature of the acid challenges associated to the erosion process, we may suppose that the laser-modified surface, created by the Nd:YAG laser on the parameters used in this study, may have been rapidly removed, offering no long-term protection. In this sense, future investigations should focus on changing the parameters of Nd:YAG laser in order to achieve a laser-modified structure not only at the surface but also a few micrometers in depth. This could potentially increase the protection of the laser in the face of sequential erosive challenges. Another point that should be considered in future studies is the enamel surface's temperature increase at the time of the laser irradiation. That is because a previous investigation observed that when the temperature increase at the enamel surface was higher than $650{ }^{\circ} \mathrm{C}$, instead of a more acid-resistant structure, there is the formation of $\alpha$ and $\beta$-TCP, which in fact are more soluble than the hydroxyapatite [32].

It was demonstrated that the application of a $2 \%$ $\mathrm{NaF}$ neutral gel followed by a high-power laser irradiation increased fluoride deposition and uptake on enamel [19]. The authors proposed two mechanisms to explain this effect. One would be related to the thermal effect of the laser, and the other to the laser-induced surface alterations, such as increased roughness, which would create additional sites for fluoride retention. During this study, however, the association of fluoride with Nd:YAG laser irradiation did not exhibit an improved protective effect when compared to fluoride alone. Considering the results of the present study, it may hypothesize that these additional fluoride deposits, if any, may have been rapidly dissolved by the low $\mathrm{pH}$ of the acid challenge $[6,25,33]$.

In the present study, as opposed to previous findings [34, 35], stannous chloride did not act in synergy with fluoride, as the gel containing $\mathrm{F}+\mathrm{Sn}$ showed less protection than the gel containing F only. One reason for this different outcome may be related to the vehicle used. In this investigation, it was chosen to add the active ingredients in a gel formulation, in order to simulate an in-office product; nevertheless, in previous investigations, the fluoride and stannous chloride were used as solutions. It can be speculated that the viscosity of the gel somewhat jeopardized the mobility of Sn ions, thereby reducing its interaction with the enamel surface [36]. Alternatively, the positively charged Sn ions might have established a bond with the carboxymethyl cellulose, the anionic molecule used as a thickening agent in the gels, also reducing Sn availability. These theories, however, need to be further investigated.
Carboxymethyl cellulose is a food gum that is used by industries as a thickening and gelling agent [37]. A previous investigation showed that adding this gum to a standard citric acid solution made it possible to decrease its erosive potential by $16 \%$, due to the gum's ability to adsorb the hydroxyapatite crystals, forming a protective layer against dissolution [37]. However, it is unknown whether this protective effect may have occurred under the conditions of this study with the control gel (gel with carboxymethyl cellulose, but without active ingredients), since no group without any treatment was tested, although it should be mentioned that the control gel showed the greatest surface loss of all groups tested.

\section{Conclusions}

Within the limitations of this in vitro study, it can be concluded that the Nd:YAG laser was able to improve the protective effect of $\mathrm{F}+\mathrm{Sn}$ gel. However, the protection of both tested gels associated to laser irradiation was not different from the $\mathrm{NaF}$ gel only. Moreover, Nd:YAG laser irradiation at the parameters used was not able to protect the enamel against dental erosion.

Acknowledgments The authors would like to thank FAPESP (State of São Paulo Research Foundation, Grants \#2014/14055-4, \#2012/20632-9 and \#2011/17699-1) and LELO - FOUSP (Special Laboratory of Lasers in Dentistry at the School of Dentistry of the University of São Paulo, Brazil).

\section{References}

1. Eccles JD (1978) The treatment of dental erosion. J Dent 6(3):217221

2. Shellis RP, Addy M (2014) The interactions between attrition, abrasion and erosion in tooth wear. Monogr Oral Sci 25:32-45

3. Lussi A, Carvalho TS (2014) Erosive tooth wear: a multifactorial condition of growing concern and increasing knowledge. Monogr Oral Sci 25:1-15

4. Lussi A, Schlueter N, Rakhmatullina E, Ganss C (2011) Dental erosion - an overview with emphasis on chemical and histopathological aspects. Caries Res 45(Suppl 1):2-12

5. Huysmans MC, Young A, Ganss C (2014) The role of fluoride in erosion therapy. Monogr Oral Sci 25:230-243

6. Ganss C, Schlueter N, Klimek J (2007) Retention of KOH-soluble fluoride on enamel and dentine under erosive conditions - a comparison of in vitro and in situ results. Arch Oral Biol 52(1):9-14

7. Babcock FD, King JC, Jordan TH (1978) The reaction of stannous fluoride and hydroxyapatite. J Dent Res 57(9-10):933-938

8. Schlueter N, Hardt M, Lussi A, Engelmann F, Klimek J, Ganss C (2009) Tin-containing fluoride solutions as anti-erosive agents in enamel: an in vitro tin-uptake, tissue-loss, and scanning electron micrograph study. Eur J Oral Sci 117(4):427-434

9. Ramos-Oliveira TM, Ramos TM, Esteves-Oliveira M, Apel C, Fischer H, de Eduardo C P, Steagall W, Freitas PM et al (2014) Potential of $\mathrm{CO} 2$ lasers (10.6 microm) associated with fluorides in inhibiting human enamel erosion. Braz Oral Res 28(1):1-6 
10. Scatolin RS, Colucci V, Lepri TP, Alexandria AK, Maia LC, Galo R, Borsatto MC, Corona SA (2014) Er:YAG laser irradiation to control the progression of enamel erosion: an in situ study. Lasers Med Sci 30(5):1465-1473

11. Rios D, Magalhaes AC, Machado MA, da Silva SM, Lizarelli Rde F, Bagnato VS, Buzalaf MA (2009) In vitro evaluation of enamel erosion after Nd:YAG laser irradiation and fluoride application. Photomed Laser Surg 27(5):743-747

12. Sobral MA, Lachowski KM, de Rossi W, Braga SR, Ramalho KM (2009) Effect of Nd:YAG laser and acidulated phosphate fluoride on bovine and human enamel submitted to erosion/abrasion or erosion only: an in vitro preliminary study. Photomed Laser Surg 27(5):709-713

13. Nelson DG, Wefel JS, Jongebloed WL, Featherstone JD (1987) Morphology, histology and crystallography of human dental enamel treated with pulsed low-energy infrared laser radiation. Caries Res 21(5):411-426

14. Tagomori S, Iwase T (1995) Ultrastructural change of enamel exposed to a normal pulsed Nd-YAG laser. Caries Res 29(6):513-520

15. Castellan CS, Luiz AC, Bezinelli LM, Lopes RM, Mendes FM, De P, Eduardo C, Freitas PM (2007) In vitro evaluation of enamel demineralization after Er:YAG and Nd:YAG laser irradiation on primary teeth. Photomed Laser Surg 25(2):85-90

16. Goodman BD, Kaufman HW (1977) Effects of an argon laser on the crystalline properties and rate of dissolution in acid of tooth enamel in the presence of sodium fluoride. J Dent Res 56(10): 1201-1207

17. Gao XL, Pan JS, Hsu CY (2006) Laser-fluoride effect on root demineralization. J Dent Res 85(10):919-923

18. Tepper SA, Zehnder M, Pajarola GF, Schmidlin PR (2004) Increased fluoride uptake and acid resistance by $\mathrm{CO} 2$ laserirradiation through topically applied fluoride on human enamel in vitro. J Dent 32(8):635-641

19. Chin-Ying SH, Xiaoli G, Jisheng P, Wefel JS (2004) Effects of CO2 laser on fluoride uptake in enamel. J Dent 32(2):161-167

20. Liu Y, Hsu CY, Teo CM, Teoh SH (2013) Potential mechanism for the laser-fluoride effect on enamel demineralization. J Dent Res 92(1):71-75

21. Wiegand A, Magalhaes AC, Navarro RS, Schmidlin PR, Rios D, Buzalaf MA, Attin T (2010) Effect of titanium tetrafluoride and amine fluoride treatment combined with carbon dioxide laser irradiation on enamel and dentin erosion. Photomed Laser Surg 28(2): 219-226

22. Pancote LP, Manarelli MM, Danelon M, Delbem AC (2014) Effect of fluoride gels supplemented with sodium trimetaphosphate on enamel erosion and abrasion: in vitro study. Arch Oral Biol 59(3): 336-340
23. Ganss C, Klimek J, Schlueter N (2014) Erosion/abrasionpreventing potential of $\mathrm{NaF}$ and $\mathrm{F} / \mathrm{Sn} /$ chitosan toothpastes in dentine and impact of the organic matrix. Caries Res 48(2):163-169

24. Palazon MT, Scaramucci T, Aranha AC, Prates RA, Lachowski KM, Hanashiro FS, Youssef MN (2013) Immediate and shortterm effects of in-office desensitizing treatments for dentinal tubule occlusion. Photomed Laser Surg 31(6):274-282

25. Scaramucci T, Borges AB, Lippert F, Frank NE, Hara AT (2013) Sodium fluoride effect on erosion-abrasion under hyposalivatory simulating conditions. Arch Oral Biol 58(10):1457-1463

26. Magalhaes AC, Romanelli AC, Rios D, Comar LP, Navarro RS, Grizzo LT, Aranha ACC, Buzalaf MA (2011) Effect of a single application of TiF4 and $\mathrm{NaF}$ varnishes and solutions combined with Nd:YAG laser irradiation on enamel erosion in vitro. Photomed Laser Surg 29(8):537-544

27. Majori M, Manzon L, Pane S, Bedini R (2005) Effects of Nd:YAG laser on dental enamel. J Appl Biomater Biomech 3(2):128-133

28. Bedini R, Manzon L, Fratto G, Pecci R (2010) Microhardness and morphological changes induced by Nd:Yag laser on dental enamel: an in vitro study. Ann Ist Super Sanita 46(2):168-172

29. Kwon YH, Kwon OW, Kim HI, Kim KH (2003) Nd:YAG laser ablation and acid resistance of enamel. Dent Mater J 22(3):404-411

30. Zezell DM, Boari HG, Ana PA, de Eduardo C P, Powell GL (2009) Nd:YAG laser in caries prevention: a clinical trial. Lasers Surg Med 41(1):31-35

31. Raucci-Neto W, de Castro-Raucci LM, Lepri CP, Faraoni-Romano JJ, Gomes da Silva JM, Palma-Dibb RG (2015) Nd:YAG laser in occlusal caries prevention of primary teeth: a randomized clinical trial. Lasers Med Sci 30(2):761-768

32. Fowler BO, Kuroda S (1986) Changes in heated and in laserirradiated human tooth enamel and their probable effects on solubility. Calcif Tissue Int 38(4):197-208

33. Borges AB, Scaramucci T, Lippert F, Zero DT, Hara AT (2014) Erosion protection by calcium lactate/sodium fluoride rinses under different salivary flows in vitro. Caries Res 48(3):193-199

34. Scaramucci T, Borges AB, Lippert F, Zero DT, Aoki IV, Hara AT (2015) Anti-erosive properties of solutions containing fluoride and different film-forming agents. J Dent 43(4):458-465

35. Ganss C, Neutard L, von Hinckeldey J, Klimek J, Schlueter N (2010) Efficacy of a tin/fluoride rinse: a randomized in situ trial on erosion. J Dent Res 89(11):1214-1218

36. Meyer-Lueckel H, Colfen H, Verch A, Tschoppe P (2010) Effects of carboxymethyl cellulose-based saliva substitutes with varying degrees of saturation with respect to calcium phosphates on artificial enamel lesions. Caries Res 44(2):127-134

37. Barbour ME, Shellis RP, Parker DM, Allen GC, Addy M (2005) An investigation of some food-approved polymers as agents to inhibit hydroxyapatite dissolution. Eur J Oral Sci 113(6):457-461 